\title{
A New Policy-Making Model for Development of National Insurance Services Market Based on Resource-Based Approach
}

\author{
Mohammad Ayati Mehr ${ }^{1}$, Mohammad Haghighi ${ }^{2}$, Mohammad Ali Shah Hosseini ${ }^{3}$, Assad Allah Kurd Naij ${ }^{4}$ \\ ${ }^{1} \mathrm{PhD}$ student of Business Administration of Alborz Pardis University of Tehran, Iran \\ ${ }^{2}$ Associate Professor, Faculty of Management, University of Tehran (Supervisor and author), Iran \\ ${ }^{3}$ Associate Professor, Faculty of Management, University of Tehran, Iran \\ ${ }^{4}$ Associate Professor at Tarbiat Modares University, Iran \\ Correspondence: Mohamad Esfehani, esfehani.mohamad3@gmail.com
}

Received: February 26, 2018

Accepted: May 15, $2018 \quad$ Online Published: May 18, 2018

doi:10.5539/ibr.v11n6p127

URL: https://doi.org/10.5539/ibr.v11n6p127

\begin{abstract}
Insurance industry is one of those industries providing financial services for people that couldn't achieve a balanced development in provision of different services. In other words, insurance companies didn't have a favorable performance as compared with other countries, except for provision of services for automobile industry. This actually pinpoints that the conditions for development and penetration into this market is not that much optimal. The main objective of this study is to provide a policy-making model for the development of service market under the light of a resource-based approach and investigation of model relations. The research method applied in this study is qualitative and it follows an applied objective. The population for this study are specified to the development of the model and interview was used to identify the criteria. The sample includes insurance companies' managers and experts. These people have at least a bachelor's degree and they have more than ten years of experience of managerial work. The number of experts included in this study include 20 people using saturation limit approach. The data were analyzed using grounded theory approach. The results showed that the main phenomenon was the concept of market-orientation. In addition, the causal conditions of this study include future-orientation and technological infrastructures. In intervention part of the study, dynamism of industry has been specified. In another part related to the context, culture has been identified. The identified strategies in the field of policy-making include innovativeness, entrepreneurialism, and a positive picture of the industry. Finally, the outcome of this model was the development of the market. The main suggestion of this study was to improve social culture. Besides, it will create a trusting mechanism with regard to policy-making and therefore the required atmosphere for the development and strengthening the market will be created.
\end{abstract}

Keywords: development of the market, resource-based approach, creation of the appropriate culture in the society, developmental policy-making, grounded theory

\section{Introduction}

As we know, considering the fast-changing market that we're facing nowadays, scheduling for participating in today's markets is more difficult and complicated as compared with the past (Merrilees et al., 2011; Maydeu \& Lado, 2003). There are several factors contributing to this phenomenon. Some of them include the intensity of competition, rapid political and economic evolutions, the observed increase in business obstacles and limitations within various countries, the observed inclination toward supporting policies, developments and rapid innovations in technology and the spread of commercial advertisements (Rahim Nia et al., 2016). This has led the companies to penetrate well into the market in different areas and they could contribute to further developing it. One of the most important industries, is insurance industry. Insurance industry, as one of the most precious industries in every society, has been always contributing to increasing economic growth and development. Nowadays, in all of development-based societies, insurance is considered as an important factor in the development of the countries, because they believe that insurance has a significant contribution in various economic areas and by covering the damages due to economic activities and contributing to the development of the society, will increase stakeholders' motivation to invest more. In other words, insurance industry, as a complex of financial firms, works for its own benefit and in the direction to reduce its expenses and its 
performance is optimized to the extent that it provides the most services with minimum expenses that will lead to rapid development in the society. In the current market, companies are faced with a stressful situation and they are looking for profitability and increasing their market share through maintaining and optimizing sales. Company's stability is dependent upon its capabilities in generating superior value for market. Resource-based perspective means that competitive advantage could be realized through resources. In order to be successful in this potential market, these companies should effectively employ both their tangible and intangible assets, provided that these resources would be valuable to be scarce, difficult to be copied, be exclusive and in addition will provide stable competitive advantage and will enhance company's performance (Velean et al., 2014; Theodosiou et al., 2012; Olimpia and Racela, 2014; Alpkan et al., 2012). One of the most prominent problems in insurance industry is the lack of balanced development within various parts of the market. The insurance market in Iran is afflicted with a structural weakness in policy-making for market development; that's why this industry was successful in the field of automobile insurance for instance; however, the same insurance companies are facing severe problems in developing its market the field of treatment insurances and accidents. Improper development of these parts is regarded as lack of suitable policy-making in insurance market; because it is insurance industry that plays an important role in most of the fields such as economic development and investments and occupational security and any decrease in market development in various field illustrates lack of understanding and cultural teachings in this field. Therefore, considering lack of sufficient public awareness toward insurance coverage, it's clear that we have problems in developing insurance market, especially in areas such as effective planning and policy-making. Thus, except for compulsory insurances like third-person, development of insurance in other fields such as life insurance, responsibility insurance, etc., it experiences a slow development. This decreased the penetration coefficient if insurance in Iran, compared with the average for global and regional countries. On the other hand, insurance's penetration coefficient which is expressive of the proportion between the produced insurance right and country's gross domestic product shows the tangible or intangible relationship between insurance industry's rate of activity and a country's economics. The insurance's penetration coefficient in 2009 was equal to 1.4. This coefficient for Middle East, northern Africa, Asia and the world is $1.6,1.59,6.2$, and 7.49 respectively. Thus we can conclude that our country isn't in good condition with regard to this index. In addition, considering the growth experienced by insurance industry and development of insurance coverage, this will lead to creation of individual benefits for individuals within a society and various economic divisions; therefore, advertising policy-making should be strengthened in this industry. According to economic and social thoughts, the government should participate actively in developing the required culture of insurance and forming the necessary evolutions in order to develop insurance industry and services in the society. It's noteworthy that there isn't any similar study on the same topic, either within the country or abroad. Besides, there isn't any national or international research paper that would have investigated various dimensions of policy-making aimed at the development of insurance industry. Considering these points. The objective of this study is to provide a policy-making model following investigation of provided market policies within country's insurance industry. Thus, the value for insurance's penetration coefficient has been raised in the country and there is a possibility of faster movement toward the first rank in the region with regard to insurance's penetration coefficient.

\subsection{Theoretical Background of the Study}

Considering the increasing changes within economics and market in world domain as well as stagnation and other related problems in Iran, the development of the market for a particular product, whether a good or service, is really significant (Chen and Wang, 2010;Doz et al., 2001). Most of the producers of a good, are the suppliers of goods or providers of some kind of services; some of them have weighed various aspects of the task at first, but have encountered problems later as they attempt to develop their own market (Eric Shaw, 2012). Identification of changes in market needs and the demands made for it in different markets has contributed to implementation of market development strategy alongside continuation of economic competition (Suh \& Kim, 2014)/ the main purpose behind market development is to achieve higher levels of performance in those markets. In fact, by developing their own market, companies will be able to make use of the existing opportunities in the new markets or they'd be able to identify gaps and fill them. Thus, understanding market development strategic models will help these companies' policy-makers and planners to codify their own competitive strategies more consciously (Masrek \& Jusoff, 2009; Seyedhosseini et al., 2016; Hsiu-Fen \& Chang, 2017) policy-making in market development is more pronounced and possible in macro fields of the country and mother organizations like Central Insurance. Iran's Central Insurance and Iran's Ministry of Economics can easily contribute to the development of insurance market in Iran and increase its penetration. The thing that should be taken more seriously, is the public use of insurance and public's understanding of advantages of insurance; this needs creation of stable resources in 
insurance industry and coordination between different organizations. For instance, broadcasting organization will have a major contribution in improving the trust atmosphere and heightening people's awareness.

Most of the problems encountered with regard to the developments incurred in the development of the market is lack of sufficient information regarding national insurance industry in less-developed countries. In fact, the more we attend to perceived values for customers, the necessary conditions for market development will be met and this is one of the necessary requirements in Iran's market. With regard to policy-making, coordination and attracting market's resources is another issue that can prevent us from redundancy and this will lead to heightening efficacy and better policy-making performance in the market.

\subsection{Experimental Background of the Study}

Fabian Eggers et al. in their study in 2017 attempted to investigate the role of technology in improving market and businesses. This study showed that implementing strategic orientations like entrepreneurialism will improve company's performance and increase market development. On the other hand, information technology, especially social networking websites is capable of providing the necessary context for nosiness companies. Komarova and Velthius (2017) investigated the market development mechanisms in emerging markets. In this study, the researchers referred to the existence of financial capacities with regard to the development of local businesses. In fact, in order to develop local markets and attain its related benefits, we should focus more on supporting capacity. O'Cass, Aron, and Heirati (2015) in teir study entitled as "an investigation of the relationship between marketing mix and capacities to concentrate on the customer to achieve the best performance for new products in the market", attempted to investigate the same relationship. The results of this study show that it's better for market-oriented companies to invest more on their marketing attempts, brand name and customer relations and this will consequently lead to higher new product performance and higher company's capacity in achieving product success. Bo Rundh (2015) investigated international markets development in small and medium-sized businesses. In this study, the researcher suggests that market development requires proper alienation of company in various parts to achieve success in international markets, especially through improving performance and export behaviors. Therefore, due attention to business development will facilitate financial performance and a positive change in business companies through making use of international opportunities. Alessandra Cssar et al. (2013) have investigated the impact of trust in market development. This study declared the need for trust in order to develop markets, especially those countries that have passed civil wars and local unrests. This study has been conducted among 426 people for investigating the factors affecting economic development; the researchers suggest that legislation and policy-making has a significant impact on developing market for the companies and increasing market activity. In another study by Zhang and $\mathrm{Wu}$ (2013), the relationship between social capital and development of the new market was investigated by considering the mediating role of companies' recognition power. This research has been implemented among high-technology companies in China. The results show that trust and power are among those powerful factors influencing the relationship between social capital and new product development. Those companies who will be able to identify market gaps, will be more successful. Ishtiaq Mahmood et al. (2012) investigated the impact of applying innovative opportunities in Taiwan markets on market development. The researcher found that considering the limitation of the resources, purposefulness in applying innovations, will enhance innovation culture; i.e. focus on innovation will provide the necessary context for companies to develop their own market. Eric Shaw (2012) investigated marketing strategies by focusing in market development approach. The researcher found that managers' approach in designing business strategies will provide more success for the businesses; this, the researchers attempted to consider manager's attitude for developing and strengthening market and it made use of business strategies in order to better orient market development.

\section{Methodology}

This study follows a qualitative approach and it makes use of systematic grounded theory as the research technique. Grounded theory is a kind of qualitative research method which attempts to identify concepts, themes and finding the relationship between data through organizing them and then provides a theory based on the data (Bazargan, 2008).This systematic grounded theory armpits to provide a model with an integrated approach. First it tries open coding, then closed and finally selective. In other words, this study is considered as heuristic based on its nature and is applied considering its purpose.

The population for this study includes marketing and policy-making experts in insurance industry. These people do have active participation in insurance companies as well as university contexts. The experts participating in this study were quite experiences in the field of penetrating into the market and policy-making. These people had been the manager if insurance companies and were in charge of marketing initiatives for at least three years. In fact the 
selected people were both academically educated in marketing and policy-making and also had relevant occupational experiences. These people were selected through purposed sampling and based on the criteria mentioned by the researcher; then, using snowball sampling method, the researcher tries to increase the number of interview participants of the study. Undoubtedly these selected people were among the informed individuals in the field of developing the market for insurance industry. This sampling has been continued to the point that the researcher attains sufficient data. Considering these information, 14 interviews were done and in order to improve validity and becoming confident in the sample, five more interviews were done. The interview was a deep one and as it was said, from the $10^{\text {th }}$ interview onward, the received data were repeated; but to make sure, the interviews continued toll $19^{\text {th }}$ interview and from $14^{\text {th }}$ interview on the data were completely repeated and they have reached saturation. Data collection has started from July, 2017. The interview began with questions regarding "influential factors on the drivers of market development through policy-making approach in insurance market" (open interview) and the rest of the questions were optimal. All the interviews were recorded and were analyzed many times in order to extract the main points.

\subsection{Reliability and Validity}

Reliability refers to the adjustability of research findings. Reliability fo interviews is assessed in several stages like interview situation, transcription and analysis. Validity refers to the way the interviewer conducts the interview and asked question. In validity of transcription, we should be conscious with regard to intra-coder validity during typing texts by two people. Another method to assess the validity of the analysis, is during the categorizing stage and noticing the reported percentages by the two coding people (Bowen \& Bowen, 2008).

a) Calculating inter-coder reliability: in order to calculate inter-rater reliability, some of the interviews were selected as examples and each of them will be coded separately by two coders. Then the generated codes will be compared with each other. in order to analyze the stability researcher's coding procedure, test-retest method is used. Those codes similar are specified as congruent and those dissimilar ones are specified as incongruent. The method for calculating inter-coder reliability by the researcher in two different time intervals is like this (Kowal, 1996):

$$
\text { the percentage of inter }- \text { coder reliability }=\frac{\text { number of congruencies } \times 2}{\text { totl number of codes }} \times 100 \%
$$

The results of these coding procedures are shown in Table 1.

Table 1. calculation of inter-coder reliability

\begin{tabular}{lllllll}
\hline No. & $\begin{array}{l}\text { Name of } \\
\text { interview }\end{array}$ & the $\begin{array}{l}\text { Total number of } \\
\text { codes }\end{array}$ & $\begin{array}{l}\text { Number } \\
\text { conformities }\end{array}$ & $\begin{array}{l}\text { of } \\
\text { inconformities }\end{array}$ & $\begin{array}{l}\text { Inter-coder } \\
\text { reliability }\end{array}$ \\
\hline 1 & P5 & 86 & 34 & 26 & $79 \%$ \\
2 & P9 & 79 & 31 & 22 & $78 \%$ \\
& total & 165 & 65 & 48 & $78 \%$ \\
\hline
\end{tabular}

As it can be seen in table 1, total number of codes registered by the researchers for 165 , the total number of conformities between the codes was equal to 65 and total number of inconformities in these two times is equal to 48. Inter-coder reliability of this research was equal to $78 \%$ for the interviews. Considering that this reliability is more than 60\%, reliability of the codes is validated (Khastar, 2009).

Validity of the interviews

Three criteria of being authentic and validity (beleivability), transferability, and confidence were considered (Khastar, 2009). The following initiatives were taken to achieve each of these criteria:

Validity: the researcher has increased the validity of research data by putting sufficient time, validation of research procedure by eight experts, using two coders for coding samples of interview for making sure about the similarity of perspectives among coders, using tangible and measurable questions like writing down the range and having reminders in excel forms.

Transferability: in order to make sure with regard to transferability of research results, three experts in the area of market development that didn't participate in the study, were consulted with regard to research findings.

In all stages of work and in order to create confidence, all the details of the research and notes were recorded.

\section{Data Analysis}

The first step: open coding

Primary coding: in this step, all the key points in the interviews get a title; then all these titles are put in Table 2. 
It's noteworthy that some samples of interviews are included here for looking at the way interviews are primarily coded.

Table 2. primary coding

Interview question
In your opinion, what are
the contributing factors
in the development of
market in insurance
industry?
industry?

Sample interview response
insurance companies with regard to market planning will be a good context for influencing the market to achieve strategic objectives in the market. Therefore, continuation of investment with regard to attaining objectives will be an important guarantee in proper orientation in getting market share and market development. In addition, specifying strategic objectives will be important for companies' success and will guarantee our success.

I think that for classifying the requirements of successful development; we need to have a general look and identify inter-organizational and intra-organizational factors in the development of the market. Intra-organizational factors include human resources and updated technologies that could help the company strengthen itself and it will be used as an important leverage in optimizing activities targeted at penetrating into insurance market. On the competitors and customers. Therefore, if these factors wouldn't be considered in market development, the company wouldn't be efficient in today's markets."

"Attempting to strengthen brand in competitive markets through considering environmental variables and factors will facilitate market development for your company."

What dimensions had the "Our company will first commence upon surveying and insurance company analyzing the market of field of activity and we will considered? perform need analysis accordingly."
If you'd like to express your weaknesses in market development and increasing your penetration into the market, what are the most disregarded aspects?
I think that having organized procedures followed by other hand, external influential factors include

"Our company is looking to identify its customers' needs as the most important asset and it will attempt to gain customer satisfaction through providing products that will match their needs."

"One of the strategic objectives of our company is consideration of market share and it attempts to increase its own market share. Therefore, it attempts to provide distinguished and exclusive products and services and increase the domain of its products. This will be only feasible through supporting new ideas provided by employees"
"Incapability in creating higher value in delivered services and products, compares with the competitors, is one of the problems observed in this domain. Those companies who are participating in markets like insurance industry quickly attempt to copy each others' ideas without considering copyright. This will reduce our capabilities for participating in competitive markets."

\section{Primary codes}

- Commitment toward investing in strategic objectives and continuity of investment

- having organized procedures with regard to business objectives

$\begin{array}{llr}\text { - Regard } & \text { for } \\ \text { intra-organizational factors } & \text { like }\end{array}$

focus on human resources' requirements and organizational technologies which are considered as important for market development.

Regard for environmental competitors, customers and their need analysis

- Optimal brand image and
increasing brand awareness in competitive markets

\section{- Market need analysis}

- Continuous customers' needs analysis

Consideration for innovation in products and services

Increasing pioneering in the market spirit

- $\quad$ Supporting employees' ideas

Aggressiveness in market

\footnotetext{
"Consideration for chance is one of those issues prevalent among our managers. That's while this topic lacks application in acquiring market development

"In our company, the designed structure isn't capable of responding to environmental changes and it looks for increasing its speed and capability in adjusting itself to environmental changes. Considering my studies, the existence of structures called agile structures will facilitate responsiveness and changing the environment. That's while the organizational structures we're using nowadays are facing severe problems with regard to speeding up information current, working knowledge and organizational decisions.
}

Creating value for customers at the time of providing products or services

- Consideration for innovation and its maintenance 
Multiple secondary codes will be transformed into one conceptual code. Table $3=3$ provides the results of open coding based on secondary codes and categories.

Table 3. transforming open codes into secondary concepts

\begin{tabular}{ll}
\hline Concepts and open codes & Categories \\
\hline Motivating the public & Public acceptance of insurance \\
Incentive plans for using insurance & \\
Creating the need in the society & \\
Extra coverage in case of acceptance of the insurance plans & \\
\hline Improving technological infrastructures and consideration for the use of them & Improving technological infrastructures in marketing \\
in order to relate with the customer & \\
Using cloud computing systems for improving initiatives & \\
Using customer relationship systems & Understanding public needs \\
Speeding up customer relationship & \\
\hline Creating supplementary insurance plans & \\
Supplying public's general concerns & Macro perspective in insurance industry \\
Favorable coverage services for the public & \\
Regard for insurer's concerns & \\
\hline Strategic outlook & Regard for legal mechanisms \\
Focus on achieving long-term competitive advantage & \\
Commitment toward long-term investment and being patient & \\
\hline Provision of coherent rules with regard to representatives &
\end{tabular}

Organizing quick follow-up approaches
Creation of dispute resolution committee for speeding up resolving customers'

complaints

Regard for ethics in insurance industry

Being important for the company

Self-awareness with regard to accessible resources and how they are

distributed

Increasing customer's awareness Improving society's understanding

Teaching human resources

Improving insurance culture within socity

Provision of financial incentives for creating the desirable culture of insurance

Using national media in creating the necessary culture

Improving positive attitude toward insurance

Creation of insurance incentive plans in less-developed regions

Focus on performance standards

Standardizing insurance procedures in the industry

Disregard for concepts like chance

An organized procedure for development and improvement

Logical analysis of market framework

Reduction of environmental uncertainties

Discovering and providing logical solutions for solving market problems

Flexible organizational structure

Organizational self-efficacy Entrepreneurship capacity in insurance industry

Competent human resources

Entrepreneurship capacities

Not getting used to current situation

$\begin{array}{ll}\text { Identification of environmental opportunities } & \text { Organizational opportunism }\end{array}$

Sagacity and intelligence in responding to market needs

speed in compatibility with market procedures.

Creating a favorable brand image in the market

Powerful brands

Social responsibilities

Regard for employee's status

Creating identity for the brand

The provided value in the market

\begin{tabular}{ll}
\hline Increasing accessible resources for the companies & Ability to fundraise \\
\hline Variety in ways for attracting capital & \\
Improving relationship with various investing departments & \\
Provision of fundraising plans & Development of human resources \\
\hline Development of intellectual capital & \\
Allocation of organizational resources for research and development & \\
department & \\
Attracting organizational experts & Using organizational knowledge
\end{tabular}


Creation of an open environment in the organization

Speed in transferring the idea to service or product

Holding brainstorming meetings

Using technology-based systems

The penetration of information technology

Focus on the technology

Using modern technologies

Investing in technology

Provision of on-time and speedy services

The quality of services

Concern for responding to customers' needs

Widespread services

Higher access to insurance services

High number of insurance branches

Variety in providing services

Covering insurer's expectations

Competitiveness of insurance services

Facilitation of requests

Relationship between various segments of the market Coordination between various segments of the market

Strengthening relationship with different parts of service industries

The necessity for other parts of the industry to make use of insurance services

The existence of administrational regulations in the industry

Regard for ethical responsibilities in insurance industry

Consistent pricing policies in insurance industries

Selection of the target market

Production, distribution and promotion of products

Application of environmental information

Creation of market research team

Improving technical knowledge in marketing segment

Creation of sustainable value

Expansion of intelligence within organization

Inter-task coordination within the organization

Long-term focus on the market

Change management

Identification of customers' future needs

Supplying customers' needs

Designing and providing products

Creation of superior value among customers

Applying customer relationship management

Continuous evaluation of brand's good reputation from customer's perspective

Codification of strategic objectives for customer brand

Identification of value from customer's perspective

Improving satisfaction and loyalty among customers

Creation and maintenance of an information bank for customers

Increasing customer's loyalty

Identification of preferred points in the mind of future customers

Provision of favorable services for customers

Creation of value among customers

Analysis of current customers' preferred point

Fast responsiveness to market requirements Market analysis

Following similar service industries

Consideration for risk

Analyzing industry's growth

Decoding insurers' behaviors

Continuous search in the industry

Gathering information from dissatisfied customers

Central insurance's increased support of insurance companies

Commitment of insurance contracts in supporting central insurance

Central insurance's guarantees

Clarification of central insurance's initiatives

Justice in paying debts

Financial liabilities

Speeding up the process of paying possible damages

Consideration for financial liabilities

Regard for the satisfaction of insurers with regard to paying the liabilities

Consideration for public financial liabilities

\subsection{Shaping the Main Categories}

After defining the categories, the next stage is structuring main categories of the theory that are included in Table 4 . 
Table 4. macro and micro categories

\begin{tabular}{|c|c|c|c|}
\hline Micro categories & Category's code & General categories & Category's code \\
\hline General acceptability of insurance & B1 & Market development & $\mathrm{C} 1$ \\
\hline Understanding insurance's need & B2 & & \\
\hline Organizational perspective & B 3 & Futurism & $\mathrm{C} 2$ \\
\hline Long-term objectives & B4 & & \\
\hline Penetration of information technology & B5 & Consideration for industry's infrastructures & $\mathrm{C} 3$ \\
\hline Powerful brands & B6 & & \\
\hline Entrepreneurship capacity & B7 & Entrepreneurialism & $\mathrm{C} 4$ \\
\hline Organizational opportunism & B8 & & \\
\hline Improving understanding gained from society & B9 & Creating culture within society & $\mathrm{C} 5$ \\
\hline Standardizing industrial procedures & $\mathrm{B} 10$ & Industry's dynamism & C6 \\
\hline Regular and coherent framework of the industry & B11 & & \\
\hline Strengthening legalism in industry & $\mathrm{B} 12$ & & \\
\hline Capability of fundraising & B13 & & \\
\hline Development of organizational capitals & B14 & Innovation-oriented & C7 \\
\hline Applying organizational knowledge & B15 & & \\
\hline Favorable financial liability & B16 & Positive picture from industry & $\mathrm{C} 8$ \\
\hline Central insurance's guarantees & B17 & & \\
\hline The quality of favorable services & B18 & & \\
\hline Coordination between different segments of the market & B19 & Market orientation & C9 \\
\hline Supplying customer demands & B20 & & \\
\hline Improving technological infrastructures in marketing & B21 & & \\
\hline Market analysis & B 22 & & \\
\hline
\end{tabular}

When a category was identified, the analyst is able to define it based on its features and particular dimensions. Through defining particular features of each category, we can specify that. The task of features in grounded theory is providing more details regarding each category.

\subsection{Second Step: Axial Coding}

Axial coding comprises the second step of analysis in grounded theory. The objective of this stage is to establish a relationship between generated categories (in open coding stage). This will be done based on paradigm model and facilitates the task for theoretician. The basis of relating procedure in axial coding is the expansion of one if the categories (Dana'ee Fard et al., 2004). In Figure 1, axial coding is illustrated in the form of a framework.

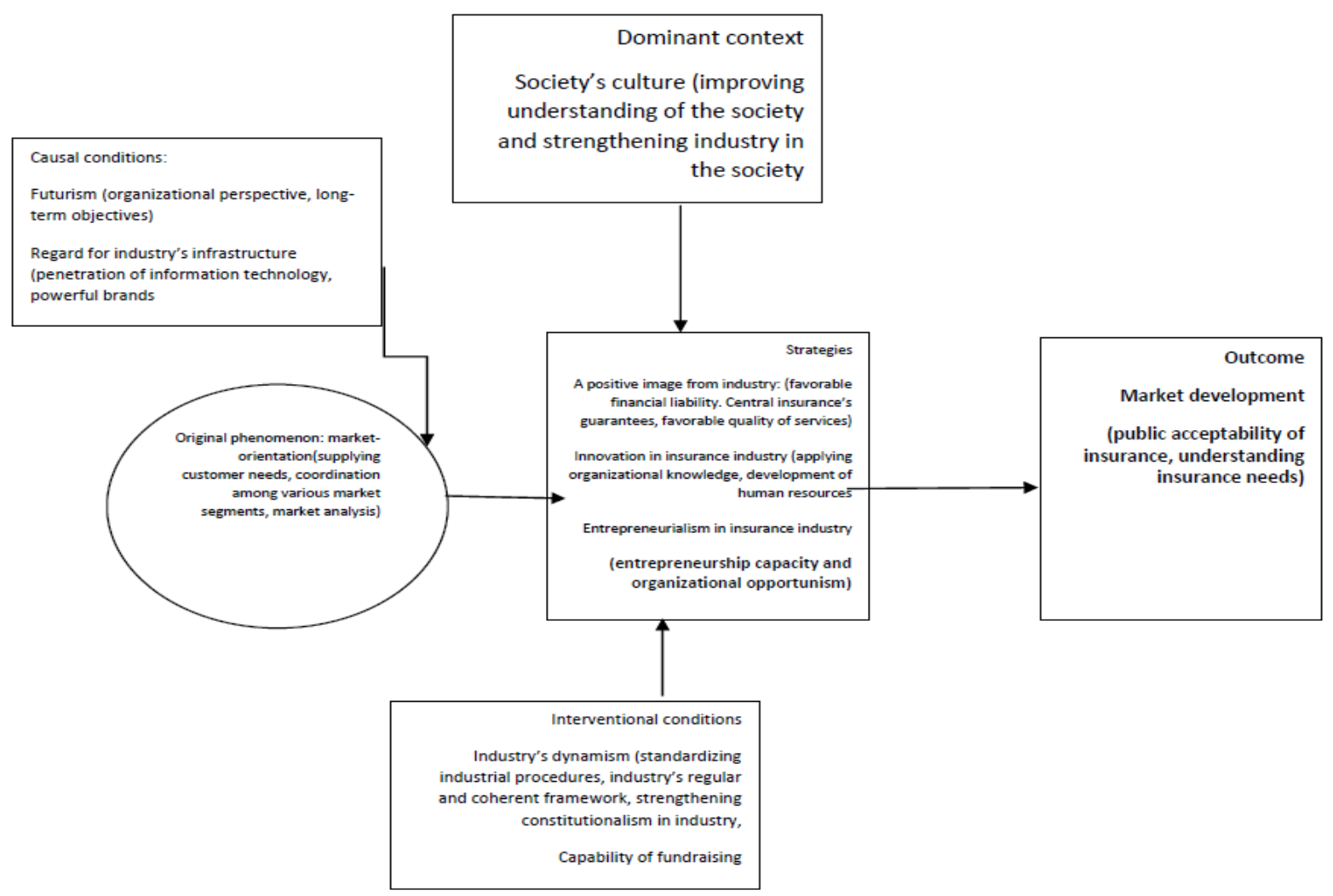

Figure 1. axial coding based on the model 


\subsection{Third Step: Theorizing Stage}

As it can be seen in figure 1, the topic of providing a model with regard to market development entails intricate relations; in fact, the causal conditions in this study include futurism which will create the necessary conditions for market development. Market orientation, will provide the necessary information regarding the positive picture of industry, innovation in industry and entrepreneurship in insurance industry that is known as model strategies. On the other hand, industry's dynamism is another factor contributing to the strengthening of strategies. On the other hand, the context of organization which is illustrative of society's culture will help to develop the market through the use of strategies and organizational strengthening.

\subsection{Defining Model's Categories}

\subsubsection{Market Development}

It refers to the improvement of insurance industry with regard to business processes in the country. In fact, market development implicates balanced share and development within various active segments in insurance industry and within national markets. One of the challenging issues in developing the market, is developing a kind of balance that should be considered as a prerequisite for improving public acceptability and understanding the necessity of this industry for continuing economic, occupational and social activities by the companies. The following is taken from an expert interview:

"Undoubtedly, in order to improve economic indices in business market, we require a consideration toward triggering public acceptability with regard to the importance of insurance for economic activities. In case that policy-making in insurance industry requires creation of need and understanding for that, it will consequently increase public acceptability of various branches of insurance industry which will provide the necessary context for improving market development."

\subsubsection{Society's Culture}

The culture of each society shows the accepted values, beliefs and norms by those people living in it. In case that one branch of initiatives will be compatible with society's values, therefore, that branch will be most accepted by the public. According to one of the experts:

"An important issue to be considered in insurance industry, its society's culture. If society's culture is ready to accept insurance and insurance-related initiatives in branches like fire, natural events, etc., it will create the necessary atmosphere for improving prosperity of participation in insurance industry."

\subsubsection{Industry's Dynamism}

An important issue in market development that should be considered is the level of participation of that industry in the society. Dynamism shows activities, initiatives, investments and other similar issues in the society. According to one of the experts:

"If we'd like to have a growing market in insurance industry, its frameworks should be established beforehand; in other words, the necessary standards with regard to business processes should be established and codified. Legalism in the industry as well as capability of fundraising are other factors contributing to market development."

\subsubsection{Entrepreneurialism}

The ability to identify opportunities is the main ingredient of entrepreneurship and it has been investigated through many years by different companies and continuous identification of new opportunities in knowledge-based and technology-based companies can be a necessary competitive advantage:

"Our company has established a department called environmental scanning in order to improve the capability of identifying opportunities. The main objective of this section is increasing the purposefulness of initiatives by increasing new initiatives in competitive market and identifying the market that seems that it has been depressed recently."

\subsubsection{Positive Image from Industry}

Something that should be considered here is the public attitude toward insurance industry and companies will contribute to the formation of a positive image in the market through creating a trusting atmosphere. This image shows public's understanding with regard to the activities done in insurance industry in order to help various segments of the society. According to one of experts:

"Trust and ethics is a topic that should be considered in insurance industry with regard to as compared with the competitors market activities. In fact, if the main purpose of policy-making will be directing companies toward 
consideration of ethics, this issue will facilitate creation of a positive image in the society. On the other hand, strengthening services and quality and increasing liability toward the resources is among those issues that will directly contribute to development of the market."

\subsubsection{Innovation-Orientation}

It refers to the novelty of ideas, methods, structures, behaviors, theories, cultures, technologies, and skills. Innovation also refers to the knowledge bases that were used for creation of new products and transfer, production, and distribution services for the administration and management of the societies and various organizations. An expert says:

"Lack of capability in creating higher values in provided products and services for the customers, as compared with the competitors is one of the apparent problems in this area. Those companies participating in medicine production in markets similar to our industry, would quickly copy services and products through reverse engineering without considering copyright and this will preclude us from being capable of participating in competitive markets."

\subsubsection{Futurism}

Futurist companies emphasize on the creation of sustainable competitive advantage in more than one period instead of realizing financial short-term expectations. According to one of the experts:

"Policy-making in companies have been always implemented considering the long-term outlook and it attempts to achieve its strategic objectives through applying a holistic look and equipping various departments."

\subsubsection{Industry's Infrastructures}

Another issue that requires investment and attention in today's markets, is the company's technological infrastructures. In other words, it is the company's infrastructures that will orient activities and companies toward market and market orientation.

"Undoubtedly, companies need to develop their modern technologies in order to strengthen their marketing initiatives, gathering information and understanding needs. These technologies make it possible to gain a better understanding of the company's environment for determining the next strategies."

\subsubsection{Market Orientation}

Market orientation is an organizational culture with maximum efficiency and effectiveness which provides the necessary behaviors and performances for creation of superior values among customers and consequently it will result in continuous superior performance for the business. Narver and Slutter (1990) define market orientation as entailing three behavioral aspects including customer orientation, competitor orientation and inter-task coordination and two decision criteria including long-term focus and profitability. One of the experts says:

"I'm saying it for sure and for $100 \%$ that companies have disregarded their won market and they will never achieve their own strategic objectives and they will be discussed in this domain as the followers and none of them would be mentions as an influential brand."

\section{Discussion and Conclusion}

Considering and strengthening the market, especially in the insurance domain is one of the important and key issues in improving and managing risk and investment in the society. Considering the functions of insurance in Iran, except for Third-person insurance, insurance industry was never successful in expanding its market. This fact validates the point that insurance industry hasn't been successful in improving its penetration and consistent penetration within different segments of the market. It seems that the macro strategies of insurance industry haven't been successfully implemented in this market and this endangered market's strengthening and development. This problem requires attention from different parts of the society toward policy-making in this domain in order to increase its penetration and market expansion. However, as it was said in the paper, the lower penetration rate observed in the society is not exclusively related to lack of good performance in insurance industry and insurance institutions. on the contrary, lack of optimal coordination among national; economic factors, weakness of insurance culture development, inappropriateness of insurance fees, lack of consideration toward the significance of insurance in having a healthy economics and finally the weakness observed toward effective policy-making and lack of widespread and awareness-increasing advertisement are among the factors contributing to slow development of this rate in Iran. Codification of appropriate strategies in this area requires positive macro perspectives toward insurance industry and coordination between different parts. Therefore, the main objective of this study was to provide a policy-making model for the development of national insurance services market. In this study, the researcher tried to make used of a qualitative approach for providing a proper 
policy making in order to penetrate into the market. One of the important parts for gathering fata that was considered as significant in this study was the topic of interview. The researcher could develop a final model regarding market development by using a grounded theory comprised of six parts. In fact, this model attempts to argue that market development is dependent upon strategies for the creation of a positive image, innovation orientation and entrepreneurship orientation. On the other hand. The strategies are influences by the main phenomenon, i.e. market orientation and intervening factors like dynamism of the industry and the context of society which is culture. Finally, the main phenomenon, being market orientation is influenced by organizations' futurism and industry's infrastructures. Eventually, this research suggests that insurance companies should attempt to clarify their own perspectives and long-term objectives specified in their planning initiatives and they also should consider powerful companies as well, so as not to waste their time and energy. In addition, it is suggested that we should use technology and web-based services for policy-making. Using cloud computing systems for speeding up, and using web-based systems for improving relationships are among $\mathrm{t}=\mathrm{other}$ factors to be considered in this relationship. On the other hand, it is argued that using national potentials like national media will $b$ effective in crating the necessary culture to make use of insurance and its advantages. In fact, using national television, using national capacities in providing incentives for using country's insurance and the necessity of that, increasing public awareness with regard to insurance mechanisms and coherent advertisement in social networking websites by central insurance to cover various branches of insurance are among other initiatives to be taken. Another recommendation is to use those injured and damaged people's experiences in order to create an awareness of insurance services and benefits and central insurance should have a more active role in this domain.

\section{References}

Alessandra, C., Pauline, G., \& Sam, W. (September, 2013). Legacies of violence: trust and market development. Journal of Economic Growth, 18(3), 285-318. https://doi.org/10.1007/s10887-013-9091-3

Alpkan, L., Mehmet, Ş., \& Yüksel, A. (2012). Market Orientation, Ambidexterity and Performance Outcomes'. Social and Behavioral Sciences, 41, 461-468. https://doi.org/10.1016/j.sbspro.2012.04.056

Bo, R. (2016). The role of packaging within marketing and value creation. British Food Journal, 118(10), 2491-2511. https://doi.org/10.1108/BFJ-10-2015-0390

Chen, M. K., \& Wang, S. C. (2010). The critical factors of success for information service industry in developing international market: using analytic hierarchy process (AHP) approach. Expert Systems with Applications, 37(1), 694-704. https://doi.org/10.1016/j.eswa.2009.06.012

Doz, Y., Santos, J., \& Williamson, P. (2001). From Global to Metanational: How Companies Win in the Knowledge Economy, Harvard Business School Press, Boston, MA.

Eric, H. S. (2012). Reflections on The History of Marketing Thought. Journal of Historical Research in Marketing, 1(2), 330-345.

Fabian, E., Isabella, H., Sascha, K., \& Thomas, N. (April, 2017). Technologies That Support Marketing and Market Development in SMEs Evidence from Social Networks. Technology and Innovation in Small Business: A Special Issue with Technovation, 55(2), 270-302

Hsiu-Fen, L., \& Kai-Lin, C. (2017). Key success factors of international market development: An empirical study of the Taiwan bulk shipping industry. Maritime Business Review, 2(2), 79-98. https://doi.org/10.1108/MABR-09-2016-0025

Komarova, N., \& Olav, V. (2017). Local contexts as activation mechanisms of market development: contemporary art in emerging markets. Journal Consumption Markets \& Culture, 21(1).

Masrek, M. N., \& Jusoff, K. (2009). The effect of information technology infrastructure flexibility on intranet effectiveness. Computer and Information Science, 2(2), 57-67. https://doi.org/10.5539/cis.v2n2p57

Maydeu-Olivares, A., \& Lado, N. (2003). Market orientation and business economic performance: A mediated model. International Journal of Service Industry Management, 14(3), 284-309. https://doi.org/10.1108/09564230310478837

Merrilees, B., Rundle-Thiele, S., \& Lye, A. (April, 2011), Marketing capabilities: Antecedents and implications for B2B SME Performance. Industrial Marketing Management, 40(3), 368-375. https://doi.org/10.1016/j.indmarman.2010.08.005

Nima, H., \& Aron O'Cass (2015). Supporting new product commercialization through managerial social ties and 
market knowledge development in an emerging economy. Asia Pacific Journal of Management.

Olimpia, C. R. (2014). Customer orientation, innovation competencies, and firm performance: A proposed conceptual model. Social and Behavioral Sciences, 148, 16-23

Rahim, N. F., \& Zare'e, A. (2016). An Investigatuon of the Impact of International Marketing strategies on Decision making and Performance of Saffron Exporting companies. Third International Conference on Management and Industrial Engineering, Frankfurt, Germany, 1-18.

Seyedhosseini, S. M., Esfahani, M. J., \& Ghaffari, M. A. (2016). novel hybrid algorithm based on a harmony search and artificial bee colony for solving a portfolio optimization problem using a mean-semi variance approach. Journal of Central South University, 2016 Jan; 23(1), 181-188.

Suh, Y., \& Kim, M. S. (2014). Internationally leading SMEs vs internationalized SMEs: evidence of success factors from South Korea. International Business Review, 23(1), 115-129. https://doi.org/10.1016/j.ibusrev.2013.03.002

Theodosiou, M., Kehgias, J., \& Katsikea, E. (2012). Strategic orientations, marketing capabilities and firm performance: An empirical investigation in the context of frontline managers in service organizations. Industrial Marketing Management, 41(7), 1058-1070. https://doi.org/10.1016/j.indmarman.2012.01.001

Velean, D., Aviv, S., \& Yoel, A. (2014). Conceptualization of MILE Orientation (Market Innovative Learning Entrepreneurial) for Global Businesses. Social and Behavioral Sciences, 109, 837-840. https://doi.org/10.1016/j.sbspro.2013.12.550

\section{Copyrights}

Copyright for this article is retained by the author(s), with first publication rights granted to the journal.

This is an open-access article distributed under the terms and conditions of the Creative Commons Attribution license (http://creativecommons.org/licenses/by/4.0/). 